\title{
PREVALENCE OF NON-STEROIDAL ANTI-INFLAMMATORY DRUGS (NSAIDS) USE IN MALAYSIAN ADULTS AND ASSOCIATED FACTORS: A POPULATION-BASED SURVEY
}

\author{
*S Maria Awaluddin, Noor Ani Ahmad, Balkish Mahadir Naidu, Muslimah Yusof, Mohamad Aznuddin Abd Razak \\ and Mohd Kamal Ariff Abdul Ghani
}

Institute for Public Health, National Institutes of Health, Ministry of Health Malaysia, Jalan Bangsar, 50590 Kuala Lumpur, Malaysia.

* Corresponding author:

S Maria Binti Awaluddin

Email: smaria@moh.gov.my

\begin{abstract}
Chronic use of non-steroidal anti-inflammatory drugs (NSAIDs) is associated with adverse effects. However, NSAIDs are among the most popular pain killers and easily available over the counter. This study aimed to determine the prevalence of NSAIDs use in Malaysian adults and among those with chronic diseases such as arthritis, kidney disease, hypertension, heart disease and asthma. It also examined the factors associated with NSAIDs use. Data from the National Health Morbidity Survey (NHMS) 2011, a nation-wide survey was analysed. A total of 18231 respondents aged 18 years and above responded to this module. Multivariate logistic regression was used to investigate the association between NSAIDs use and associated factors. The overall prevalence of NSAIDs use among Malaysian adults was $14.2 \%(95 \% \mathrm{Cl} 13.3-15.1)$. Of the respondents, $4.2 \%$ $(95 \% \mathrm{Cl} 3.8-4.7)$ took NSAIDs once daily. NSAIDs use was highly associated with those who were ever-told to have arthritis (aOR: 3.03; 95\% Cl 2.60-3.52) and have difficulty of performing daily activities or work (aOR: 2.06; 95\%Cl 1.86-2.28). Those who were ever-told to have kidney disease (aOR: 2.36; $95 \% \mathrm{Cl} 1.74-3.20)$, ever-told to have asthma (aOR: 1.36; 95\%Cl 1.171.58), ever-told to have heart disease (aOR: 1.34; 95\% Cl 1.08-1.65), known hypertension (aOR: 1.22; 95\% Cl 1.08-1.37) also were associated with NSAIDs use. By socio-demographic profiles, NSAIDs use was positively associated with those who have government benefit scheme or private health insurance (aOR: 1.44; $95 \% \mathrm{Cl} 1.31-1.58)$, higher education level (aOR: 1.35; $95 \% \mathrm{Cl}$ 1.20-1.51), higher household income (aOR: 1.26; 95\% Cl 1.11-1.44, aOR: 1.12; 95\% Cl 1.02-1.24), currently working (aOR: 1.25; 95\% CI 1.13-1.39) and female (aOR: 1.17; 95\% CI 1.07-1.28). NSAIDs use was less likely among those aged 60 years and above (aOR: 0.83; 95\% Cl 0.72-0.97), Chinese (aOR: 0.41; 95\% Cl 0.36-0.47) and 'Others' ethnicity (aOR: 0.82; 95\% Cl 0.67-0.99) compared to Malay ethnicity. NSAIDs use is prevalent in Malaysian adults and associated with co-morbidities and higher socio-demographic status, thus appropriate awareness should be promoted and highlighted in the community.
\end{abstract}

Keywords: non-steroidal anti-inflammatory drugs, NSAIDs use, NHMS, prevalence, Malaysia.

\section{INTRODUCTION}

The non-steroidal anti-inflammatory drugs (NSAIDs) are used for their analgesic, antipyretics and inflammatory properties. The mechanism is via inhibition of cyclooxygenase enzyme (COX) which further inhibits prostaglandin synthesis. Through this similar pathway, NSAIDs can cause multi-systems NSAIDs related side effect with a wide range level of severity ${ }^{1,2}$. The COX-2-selective inhibitors (COXIBS) were introduced later to reduce the adverse effect however, previous studies have shown that that it still has some similar complication as non-selective NSAIDs ${ }^{3}$. NSAIDs are still widely used as a medication for any type of pain such as headache and musculoskeletal pain even though there were evidence on the association of prolonged use of NSAIDs with adverse reaction in certain high risk group $^{4,5}$.

As being such commonly consumed medication among adult population, the prevalence of NSAIDs use ranged from $17 \%$ to $30 \%$ in the United States and Netherlands ${ }^{6,7}$. The prevalence of NSAIDs use captured both from the prescribed NSAIDs and also over-the-counter (OTC) NSAIDs ${ }^{6,7}$. NSAIDs were commonly use among those who have arthritis as they were having difficulty in working or daily activities due to pain which observed in previous studies $^{8,9}$. Another study observed NSAIDs use was higher among female and those aged above 30 years compared to the younger counterpart ${ }^{8}$. There were $8.2 \%$ community dwelling aged 70 years and above living in Sydney used NSAIDs regularly ${ }^{10}$. NSAIDs were also commonly use among the older person with co-morbidities such as cardiovascular disease/stroke, heart disease, hypertension and kidney disease ${ }^{11}$. Those who were having health insurance coverage was associated NSAIDs use ${ }^{11}$.

According to the Malaysian Statistics on Medicine Survey 2008, the top three prescribed NSAIDs were fenamates, followed by acetic acid derivatives and related substances and coxibs. Nevertheless, the prevalence on NSAIDs use is still lacking among adult population in Malaysia especially those at higher risk 
of developing NSAIDs related complications. This study aimed to determine the prevalence of NSAIDs use in Malaysian adults and among adult with chronic diseases such as arthritis, kidney disease, hypertension, heart disease and asthma. It also examined the factors associated with NSAIDs use.

\section{METHODOLOGY}

Data from the National Health Morbidity Survey (NHMS) 2011, a nation-wide survey among Malaysian residents were used. Two stage stratified random sampling were applied in the sample selection to ensure national representativeness. The first stage was selection of enumeration blocks (EBs) and second stage was selection of living quarters (LQs). The sample size for NHMS was calculated based on the analysis requirement for each topic as described in details in the technical report ${ }^{12}$. However, for the estimation of NSAIDs use, the minimum sample required was 481 respondents for single proportion formula with expected prevalence was 0.5 , precision at 0.05 and adjustment for $20 \%$ nonresponse. Data were collected using face-to-face interview by trained data collectors. For the purpose of this study, data analysis was focused on adult population who answered module health problems. Respondents were asked "In the last 6 months, have you taken any pain killers such as Ponstan, Voltaren, Brufen, Arcoxia, Celebrex/Mobic. (Paracetamol and aspirin were not included). Respondents who answered "yes" were considered that they had used NSAIDs in the last 6 months. Further questions were asked to investigate about the frequency of NSAIDs intake whether "at least once a day", "at least once a week", at least once a month" and "less than once in a month". The socio-demographic data being collected were age, sex, ethnicity, education level and household income. Ethnicity was classified according to the ethnic groups in Malaysia where "Others" ethnicity referred to other ethnicities which not belong to major ethnicities in Malaysia. Respondents were also asked whether they have any difficulty in working or daily activities. This is proxy for physical activity limitation.

The NHMS was registered with National Medical Research Registration; (NMRR-10-757-6837) and had obtained approval from Medical Research Ethic Committee, Ministry of Health, Malaysia. The information gathered through this survey was kept confidential. Written consent was taken from the respondents before conducting the survey.

Data analyses were conducted using IBM SPSS Statistics for Windows, Version 21.0 software. The estimated prevalence of NSAIDs use in general population and by socio-demographic profiles was calculated using descriptive statistics. Multivariate logistic regression was used to investigate the association between NSAIDs use and socio- demographic variables including co-morbidities as observed in the literature reviews. Simple logistic regression was conducted first before all the variables were included in the final multivariate logistic regression model using method "Enter". The findings were presented as adjusted odd ratios (aORs) with $95 \%$ confidence intervals $(\mathrm{Cl})$, and a pvalue $<0.05$ was considered significant.

\section{RESULTS}

The general response rate for NHMS study was 88.2 $\%$. The total respondents for this module were 18,168 people. Of these, $53.2 \%$ were male respondents and $46.8 \%$ were female respondents. By ethnicity, $57.0 \%$ were Malays, $19.3 \%$ were Chinese, $8.0 \%$ were Indians, $9.5 \%$ other Bumiputeras and $6.2 \%$ were "Others" which referred to other ethnicities which not belong to the major ethnicities. The above ethnic breakdown was nearly similar with the findings in Malaysian Census 2010.

The overall prevalence of NSAIDs use among Malaysian adults within the past 6 months was $14.2 \%$ $(95 \% \mathrm{Cl} 13.3-15.1)$ which can be inferred to an estimated 2,512,417 respondents. By gender, the prevalence of NSAIDs use was higher among females $(15.3 \%)$ compared to males $(13.0 \%)$. The prevalence of NSAIDs use by other socio-demographic categories was shown in Table 1.

In term of the frequency of NSAIDs intake, $4.2 \%$ $(95 \% \mathrm{Cl} 3.8-4.7)$ took NSAIDs once daily, $2.2 \%(95 \% \mathrm{Cl}$ 1.9-2.5) took once a week, $3.2 \%(95 \% \mathrm{Cl} 3.0-3.8)$ once a month and $4.1 \%(95 \% \mathrm{Cl} 3.7-4.6)$ took less than once a month.

Table 2 shows prevalence of NSAIDs use among those with chronic diseases such as known hypertension $(18.87 \%$; $95 \% \mathrm{Cl} 16.93-20.97)$, ever-told heart disease $(23.65 \%$; $95 \% \mathrm{Cl} 19.65-28.19)$, ever-told asthma (20.08\%; $95 \% \mathrm{Cl}$ 17.25-23.24), ever-told stroke $(18.48 \% ; \quad 95 \% \mathrm{Cl} 12.25-26.91)$, ever-told arthritis (34.03\%; 95\% Cl 29.90-38.43) and ever-told kidney disease $(31.57 \%$; $95 \% \mathrm{Cl} 24.62-39.45)$.

Table 3 shows the result of multivariate analysis for factors associated with NSAIDs use among Malaysian adults. NSAIDs use was highly associated with those who were ever-told to have arthritis (aOR: 3.03; $95 \% \mathrm{Cl} 2.60-3.52$ ) and have difficulty of performing daily activities or work (aOR: 2.06 ; $95 \% \mathrm{Cl} 1.86$ 2.28). Those who were ever-told to have kidney disease (aOR: $2.36 ; 95 \% \mathrm{Cl} 1.74-3.20$ ), ever-told to have asthma (aOR: $1.36 ; 95 \% \mathrm{Cl} 1.17-1.58)$, ever-told to have heart disease (aOR: $1.34 ; 95 \% \mathrm{Cl} 1.08-1.65$ ), known hypertension (aOR: 1.22; 95\% Cl 1.08-1.37) also were associated with NSAIDs use. By sociodemographic profiles, NSAIDs use was positively associated with those who have government benefit scheme or private health insurance (aOR: 1.44; $95 \% \mathrm{Cl} 1.31-1.58$ ), higher education level (aOR: 1.35; 
95\% Cl 1.20-1.51), higher household income (aOR: 1.26; $95 \% \mathrm{Cl} 1.11-1.44$, aOR: 1.12 ; $95 \% \mathrm{Cl} 1.02-1.24$ ), currently working (aOR: $1.25 ; 95 \% \mathrm{Cl} 1.13-1.39$ ) and female (aOR: $1.17 ; 95 \% \mathrm{Cl} 1.07-1.28$ ). NSAIDs use was less likely among those aged 60 years and above (aOR: $0.83 ; 95 \% \mathrm{Cl} 0.72-0.97$ ), Chinese (aOR: 0.41; 95\% Cl 0.36-0.47) and 'Others' ethnicity (aOR: 0.82; $95 \% \mathrm{Cl}$ 0.67-0.99) compared to Malay ethnicity.

Table 1: Bivariate analyses of factors associated with NSAIDs use among Malaysian adults.

\begin{tabular}{|c|c|c|c|c|c|c|c|}
\hline \multirow[t]{3}{*}{ Variables } & \multicolumn{6}{|c|}{ NSAIDs Use } & \multirow[t]{3}{*}{ p-value } \\
\hline & \multicolumn{3}{|c|}{ Yes } & \multicolumn{3}{|c|}{ No } & \\
\hline & $n$ & $\%$ & $(95 \% \mathrm{Cl})^{\#}$ & $\mathrm{n}$ & $\%$ & $(95 \% \mathrm{Cl})^{\#}$ & \\
\hline \multicolumn{8}{|l|}{ Sex } \\
\hline Male & 1247 & 13.03 & $(12.01-14.11)$ & 7263 & 86.97 & $(85.89-87.99)$ & 0.001 \\
\hline Female & 1505 & 15.33 & $(14.12-16.61)$ & 8153 & 84.67 & $(83.39-85.88)$ & \\
\hline \multicolumn{8}{|l|}{ Age } \\
\hline$<60$ yrs & 2377 & 14.35 & $(13.40-15.37)$ & 13040 & 85.65 & $(84.63-86.60)$ & .067 \\
\hline$\geq 60 \mathrm{yrs}$ & 375 & 12.59 & $(10.99-14.39)$ & 2376 & 87.41 & $(85.61-89.01)$ & \\
\hline \multicolumn{8}{|l|}{ Ethnicity } \\
\hline Malay & 1782 & 16.90 & $(15.82-18.02)$ & 8572 & 83.10 & $(81.18-84.18)$ & $<0.001$ \\
\hline Chinese & 276 & 7.34 & $(6.31-8.53)$ & 3231 & 92.66 & $(91.47-93.69)$ & \\
\hline Indian & 307 & 21.01 & $(18.06-24.30)$ & 1151 & 78.99 & $(75.70-81.94)$ & \\
\hline Other Bumiputeras & 252 & 15.18 & $(11.22-20.23)$ & 1470 & 84.82 & $(79.77-88.78)$ & \\
\hline Others & 135 & 10.82 & $(8.07-14.37)$ & 992 & 89.18 & $85.63-91.93)$ & \\
\hline \multicolumn{8}{|l|}{ Education } \\
\hline $\begin{array}{l}\text { Non-formal \& } \\
\text { primary }\end{array}$ & 730 & 11.57 & $(10.33-12.93)$ & 1991 & 88.43 & $(87.07-89.67)$ & $<0.001$ \\
\hline $\begin{array}{l}\text { secondary \& } \\
\text { tertiary }\end{array}$ & 1991 & 15.21 & $(14.17-16.31)$ & 10134 & 84.79 & $(83.69-85.83)$ & \\
\hline \multicolumn{8}{|l|}{$\begin{array}{l}\text { Covered (Government } \\
\text { GL \& Private } \\
\text { Insurance) }\end{array}$} \\
\hline Yes & 1474 & 16.54 & $(15.34-17.81)$ & 6591 & 83.46 & $(82.19-84.66)$ & $<0.001$ \\
\hline No & 1266 & 12.08 & $(10.89-13.38)$ & 8742 & 87.82 & $(86.62-89.11)$ & \\
\hline \multicolumn{8}{|l|}{ Currently Working } \\
\hline Yes & 1809 & 14.96 & $(13.87-16.13)$ & 9496 & 85.04 & $(83.87-86.13)$ & $<0.001$ \\
\hline No & 941 & 12.57 & $(11.52-13.70)$ & 5913 & 87.43 & $(86.30-88.48)$ & \\
\hline \multicolumn{8}{|l|}{ Household income } \\
\hline$<\mathrm{R} 2300$ & 1116 & 12.58 & $(11.52-13.73)$ & 7206 & 87.42 & $(86.27-88.48)$ & 0.001 \\
\hline $2300-5599$ & 1099 & 14.96 & $(13.71-16.31)$ & 5714 & 85.04 & $(83.69-86.29)$ & \\
\hline > RM 5599 & 537 & 15.93 & $(13.94-18.14)$ & 2496 & 84.07 & $(81.86-86.09)$ & \\
\hline \multicolumn{8}{|l|}{$\begin{array}{l}\text { Difficulty in } \\
\text { work/activities }\end{array}$} \\
\hline Yes & 828 & 24.92 & $(22.87-27.09)$ & 2501 & 75.08 & $(72.91-77.13)$ & $<0.001$ \\
\hline No & 1921 & 11.96 & $(11.07-12.91)$ & 12904 & 88.04 & $(87.09-88.93)$ & \\
\hline
\end{tabular}

* Significant at 95\% confident interval

\# Confidence Interval

The total number of respondents is not consistent because of missing data 
Table 2: Prevalence of reported NSAIDs use in adults with chronic diseases compared with adults without chronic diseases.

\begin{tabular}{|c|c|c|c|c|}
\hline \multirow{2}{*}{ Chronic Diseases } & \multicolumn{3}{|c|}{ Prevalence of reported NSAIDs use } & \multirow[b]{2}{*}{ p-value } \\
\hline & $\mathrm{n}$ & $\%$ & $95 \% \mathrm{Cl}$ & \\
\hline \multicolumn{5}{|c|}{ Known Hypertension } \\
\hline Yes & 530 & 18.87 & $(16.93-20.97)$ & $<0.001$ \\
\hline No & 2707 & 13.48 & (12.55-14.47) & \\
\hline \multicolumn{5}{|c|}{ Ever-told Heart Disease } \\
\hline Yes & 158 & 23.65 & $(19.65-28.19)$ & $<0.001$ \\
\hline No & 2592 & 13.87 & $(12.97-14.81)$ & \\
\hline \multicolumn{5}{|l|}{ Ever-told Asthma } \\
\hline Yes & 264 & 20.08 & $(17.25-23.24)$ & $<0.001$ \\
\hline No & 2487 & 13.79 & $(12.90-14.73)$ & \\
\hline \multicolumn{5}{|l|}{ Ever-told Stroke } \\
\hline Yes & 44 & 18.48 & $(12.25-26.91)$ & 0.197 \\
\hline No & 2487 & 14.13 & $(13.22-15.08)$ & \\
\hline \multicolumn{5}{|l|}{ Ever-told Arthritis } \\
\hline Yes & 356 & 34.03 & $(29.90-38.43)$ & $<0.001$ \\
\hline No & 2395 & 13.15 & $(12.31-14.04)$ & \\
\hline \multicolumn{5}{|c|}{ Ever-told Kidney Disease } \\
\hline Yes & 76 & 31.57 & $(24.62-39.45)$ & $<0.001$ \\
\hline No & 2673 & 13.96 & $(13.06-14.91)$ & \\
\hline
\end{tabular}

\section{DISCUSSION}

The overall prevalence of NSAIDs use within the past six months among Malaysian adults was observed to be higher $(14.2 \%)$ in comparison with adults in Adelaide (11.2\%) however, still lower from the United States $(17 \%)$ and Netherlands $(30 \%)^{6,7,11}$. The overall prevalence was based on the respondent's reported NSAIDs use at least once within the past six months in this study, however other study reported based on NSAIDs use within 4 weeks which influenced the wide range of prevalence's figure ${ }^{6}$. The study also investigated the prevalence of NSAIDs use according to the frequency of NSAIDs intake. The prevalence of daily NSAIDs user in this study was $4.2 \%$ which is the highest compared to weekly user, monthly user and less than once a month NSAIDs user. A study conducted among 6500 Finnish people aged $15-74$ years observed $8.5 \%$ of the respondents took NSAIDs at daily frequency while there were $12.1 \%$ of regular NSAIDs users who took NSAIDs at least three times a week among adult population in the United States ${ }^{13,14}$. This study observed lower prevalence of daily NSAIDs users might be due to prescribing practice among healthcare providers who take more cautions in prescribing NSAIDs.

This study also identified the prevalence of NSAIDs use among adults with chronic diseases compared to adult without the chronic diseases. The prevalence of NSAIDs use was significantly higher among those with ever-told arthritis, ever-told kidney disease, known hypertension, ever-told heart disease and ever-told asthma compared to their counterparts who were without the diseases. This study observed that those with co-morbidities were more likely to use NSAIDs after controlling with socio-demographic variables in the logistic regression model. A study conducted in the United States observed that among those with moderate and severe chronic kidney disease; more than half using NSAIDs for one year or longer ${ }^{15}$. This finding should raise a concern for those who at-risk of developing complication still consuming NSAIDs regularly. Adults who were ever been told to have arthritis were more likely to use NSAIDs as a short term reliever especially during painful flares of arthritis, 16-18. Physical health problems; difficulty in performing work or daily activities also more likely to use NSAIDs besides other type of pain killers ${ }^{19}$. However, this study found no significant difference between prevalence NSAIDs user among ever-told stroke and those who do not have stroke. The possible reason for this finding is those with ever-told stroke might be included in the age group of 60 years and above where the lower prevalence of NSAIDs use was observed although the difference with those aged below than 60 years was not significant in bivariate analysis. Various studies reported that higher NSAIDs use among those with advanced age, however the study was conducted among the older person samples where comparison could not be made with the younger adults ${ }^{18,20,21}$. Those in advance age were observed having higher risk of developing NSAIDs complications as reported in previous studies ${ }^{21,22}$. After controlling with other variables, age group was found to be negatively associated with NSAIDs use. Older age defined as 60 years and above was less likely to use NSAIDs in this study. This study may suggest that those with co-morbidities and aged below 60 years were more likely to use NSAIDs. In other hand, older persons in Malaysia had been given precaution on taking NSAIDs unnecessarily or 
they were prescribed other types of pain killers. Adams at el. found no significant association of NSAIDS use with variable age in their study might be due to the cut-off age categories being used in their study ${ }^{11}$. Other studies found aged 45 to 49 years and 51 to 70 years have the highest odds of NSAIDs use compared with the younger age or the oldest age group $^{8,13}$.

Table 3a: Multivariate analysis of factors associated with NSAIDs use among Malaysian adults.

\begin{tabular}{|c|c|c|c|c|c|c|c|}
\hline \multirow[t]{2}{*}{ Variables } & \multicolumn{2}{|c|}{$\begin{array}{l}\text { Simple Logistic } \\
\text { Regression }\end{array}$} & \multicolumn{5}{|c|}{ Multiple Logistic Regression } \\
\hline & $\begin{array}{l}\text { Crude } \\
\text { OR }\end{array}$ & $(95 \% \mathrm{Cl})$ & $\begin{array}{l}\text { Wald } \\
\text { Test }\end{array}$ & df & Adjusted OR & $(95 \% \mathrm{Cl})$ & P-value \\
\hline \multicolumn{8}{|l|}{ Sex } \\
\hline Male ${ }^{\text {Ret }}$ & 1.00 & - & & 1 & 1.00 & - & \\
\hline Female & 1.08 & $(0.99-1.17)$ & 11.16 & 1 & 1.17 & $(1.07-1.28)^{*}$ & 0.001 \\
\hline \multicolumn{8}{|l|}{ Age } \\
\hline$<60$ yrs & 1.00 & - & & 1 & 1.00 & - & \\
\hline$\geq 60 \mathrm{yrs}$ & 0.87 & $(0.77-0.97)^{*}$ & 5.26 & 1 & 0.83 & $(0.72-0.97)^{*}$ & 0.002 \\
\hline \multicolumn{8}{|l|}{ Ethnicity } \\
\hline Malay Ret & 1.00 & - & 172.33 & 4 & 1.00 & - & \\
\hline Chinese & 0.41 & $(0.36-0.47)^{*}$ & 159.75 & 1 & 0.41 & $(0.36-0.47)^{*}$ & $<0.001$ \\
\hline Indian & 1.28 & $(1.12-1.47)^{*}$ & 2.38 & 1 & 1.12 & $(0.97-1.29)$ & 0.123 \\
\hline Others Bumiputeras & 0.83 & $(0.72-0.95)$ & 1.85 & 1 & 0.90 & $(0.77-1.05)$ & 0.166 \\
\hline Others & 0.66 & $(0.54-0.79)^{*}$ & 3.81 & 1 & 0.82 & $(0.67-0.99)^{*}$ & 0.046 \\
\hline \multicolumn{8}{|l|}{ Education } \\
\hline Primary and lower ${ }^{\text {Ret }}$ & 1.00 & - & & 1 & 1.00 & - & \\
\hline $\begin{array}{l}\text { Secondary and } \\
\text { tertiary } \\
\text { Covered (Government } \\
\text { GL \&Private Insurance) }\end{array}$ & 1.37 & $(1.25-1.50)^{*}$ & 25.20 & 1 & 1.35 & $(1.20-1.51)^{*}$ & $<0.001$ \\
\hline Yes & 1.54 & $(1.42-1.68)$ & 58.58 & 1 & 1.44 & $(1.31-1.58)^{*}$ & $<0.001$ \\
\hline No ${ }^{\text {Ret }}$ & 1.00 & - & & 1 & 1.00 & - & \\
\hline \multicolumn{8}{|l|}{ Currently Working } \\
\hline Yes & 1.20 & $(1.10-1.30)^{*}$ & 17.73 & 1 & 1.25 & $(1.13-1.39)^{*}$ & $<0.001$ \\
\hline No ${ }^{\text {Ref }}$ & 1.00 & - & & 1 & 1.00 & - & \\
\hline \multicolumn{8}{|l|}{ Household Income } \\
\hline$<$ R2300 Ret & 1.00 & - & 13.62 & 2 & 1.00 & - & \\
\hline $2300-5599$ & 1.24 & $(1.14-1.36)$ & 5.29 & 1 & 1.12 & $(1.02-1.24)^{*}$ & 0.021 \\
\hline > RM 5599 & 1.39 & $(1.24-1.56)$ & 13.13 & 1 & 1.26 & $(1.11-1.44)^{*}$ & $<0.001$ \\
\hline
\end{tabular}

Gender also contributed to NSAIDs use as this study found that women was positively associated with NSAIDs use and similar finding were observed in previous studies conducted in Adelaide, Norway, Brazil and Finland ${ }^{11,18,21,24}$. A review article conducted by Fillingim et al. in 2009 concluded that women have greater pain sensitivity compared to men. The study also suggested the effect of biological mechanism which influences perception of pain among women. Another recent study on pain sensitivity between male and female reported that women were more sensitive to pain stimulation ${ }^{25,26}$. These information support the finding on association of women with NSAIDs use because of the lower pain perception among women which further contributed to the likelihood of using NSAIDs compared to men $^{27}$.

Those with higher education were found to be more likely to use NSAIDs compared to those with primary level of education in this study. However, this findings contradicted with the observation in previous study where those with low education more likely to use NSAIDs ${ }^{11,13}$. The possible reason for the higher education group used NSAIDs more than the lower education because they may have some office work-related stress in higher education group which usually induces symptoms like headache and musculoskeletal pain and later requires them to use NSAIDs as pain killer. Those 
with lower education level should have more musculoskeletal pain as per nature of their work; however, the possibility of under reporting should be considered. They may not recognise the type of medication or they took herbal medicine. The similar reasons of office work-related stress or musculoskeletal pain to explain on the finding of those with higher income were more likely to use NSAIDs.

Table 3b: Multivariate analysis of factors associated with NSAIDs use among Malaysian adults (continued).

\begin{tabular}{|c|c|c|c|c|c|c|c|}
\hline \multirow[t]{2}{*}{ Variables } & \multicolumn{2}{|c|}{$\begin{array}{l}\text { Simple Logistic } \\
\text { Regression }\end{array}$} & \multicolumn{5}{|c|}{ Multiple Logistic Regression } \\
\hline & $\begin{array}{l}\text { Crude } \\
\text { OR }\end{array}$ & $(95 \% \mathrm{Cl})$ & $\begin{array}{l}\text { Wald } \\
\text { Test }\end{array}$ & df & Adjusted OR & $(95 \% \mathrm{Cl})$ & P-value \\
\hline \multicolumn{8}{|c|}{$\begin{array}{l}\text { Difficulty in Work/ } \\
\text { Activities }\end{array}$} \\
\hline Yes & 2.22 & $(2.03-2.44)^{*}$ & 195.74 & 1 & 2.06 & $(1.86-2.28)^{*}$ & $<0.001$ \\
\hline No ${ }^{\text {Ref }}$ & 1.00 & - & & 1 & 1.00 & - & \\
\hline \multicolumn{8}{|c|}{ Known Hypertension } \\
\hline Yes & 1.38 & $(1.24-1.53)^{*}$ & 10.32 & 1 & 1.22 & $(1.08-1.37)^{*}$ & 0.001 \\
\hline No ${ }^{\text {Ref }}$ & 1.00 & - & & 1 & 1.00 & - & \\
\hline \multicolumn{8}{|c|}{$\begin{array}{l}\text { Ever-told to Have Heart } \\
\text { Disease }\end{array}$} \\
\hline Yes & 1.92 & $(1.60-2.32)^{*}$ & 7.27 & 1 & 1.34 & $(1.08-1.65)^{*}$ & 0.007 \\
\hline No ${ }^{\text {Ret }}$ & 1.00 & - & & 1 & 1.00 & - & \\
\hline \multicolumn{8}{|c|}{$\begin{array}{l}\text { Ever-told to Have } \\
\text { Asthma }\end{array}$} \\
\hline Yes & 1.74 & $(1.51-2.01)^{*}$ & 15.23 & 1 & 1.36 & $(1.17-1.58)^{*}$ & $<0.001$ \\
\hline No ${ }^{\text {Ref }}$ & 1.00 & - & & 1 & 1.00 & - & \\
\hline \multicolumn{8}{|c|}{$\begin{array}{l}\text { Ever-told to Have } \\
\text { Arthritis }\end{array}$} \\
\hline Yes & 3.26 & $(2.85-3.74)^{*}$ & 207.22 & 1 & 3.03 & $(2.60-3.52)^{*}$ & $<0.001$ \\
\hline No Ret & 1.00 & - & & 1 & 1.00 & - & \\
\hline \multicolumn{8}{|c|}{$\begin{array}{l}\text { Ever-told to Have } \\
\text { Stroke }\end{array}$} \\
\hline Yes & 1.71 & $(1.22-2.40)^{*}$ & 1.30 & 1 & 1.25 & $(0.85-1.83)^{*}$ & 0.254 \\
\hline No ${ }^{\text {Ket }}$ & 1.00 & - & & 1 & 1.00 & - & \\
\hline \multicolumn{8}{|c|}{$\begin{array}{l}\text { Ever-told to Have } \\
\text { Kidney Disease }\end{array}$} \\
\hline Yes & 2.99 & $(2.26-3.96)^{*}$ & 30.38 & 1 & 2.36 & $(1.74-3.20)^{*}$ & $<0.001$ \\
\hline No ${ }^{\text {Ket }}$ & 1.00 & - & & 1 & 1.00 & - & \\
\hline
\end{tabular}

* significance $p$-value $<0.05$

Ref \& 1.00 reference group

\# adjusted for all other variables

This study found that respondents who have medically covered either by government scheme or private insurance were positively associated with NSAIDs use because it facilitates people to the prompt medical services. This finding is similar to the finding in the study conducted in Adelaide ${ }^{11}$. This group of people use NSAIDs via the doctor's prescription using the proper channel of medical services. The need for NSAIDs use will be evaluated differently according to the individual need by health care provider as compared to those who bought OTC NSAIDs.
Ethnicity was also known to be linked with NSAIDs use as Chinese ethnicity was less likely to use NSAIDs, but this finding needs to be explored further as a study conducted among Chinese immigrants in United States observed that they preferred to use their own traditional herbs ${ }^{28}$. The finding on Chinese ethnicity is similar with "Others" ethnicity. They might share the similar reason with Chinese ethnicity. The preference on using herbs according to the ethnic background is undeniable. A study conducted in the United States observed the prevalence of regular NSAIDs use between $2.9 \%$ to 
14.6\% among various ethnic groups which may support this finding ${ }^{14}$.

Limitation

This study is based on self-reported data by the respondent on the usage of NSAIDs. There is possible difficulty for the respondent with lower educational level to recognise the types of medication as certain OTC medication are not properly labelled. This study also unable to differentiate between selfmedicated NSAIDs or prescribed NSAIDs. This study used cross-sectional design, thus determination of causality cannot be assessed.

\section{CONCLUSION}

This study has found that NSAIDs is being used in Malaysian adults and higher prevalence was observed among adults with chronic diseases compared to adults without the chronic diseases. NSAIDs use was highly associated with those who ever-told to have arthritis followed by those who have difficulty performing daily works or activities. Adults with co-morbidities such as hypertensive disease, chronic renal disease, heart disease and asthma also associated with NSAIDs use. By socio demographic profiles, female, higher income groups, currently working were associated with NSAIDs use, however aged 60 years and above, Chinese and "Others" ethnicities were less likely to be associated with NSAIDs use.

\section{ACKNOWLEDGEMENT}

The authors would like to express our gratitude to the Director General of Health Malaysia for the permission on the publication of this study. The authors also thanked the Principle Investigator and NHMS team members for their contribution to the success of this study.

\section{Competing Interest}

The authors declare that they have no conflicts of interest.

\section{Authors' contribution}

All authors participated and contributed their part throughout the study, from designing the study until manuscript approval.

\section{Funding}

This study was funded by Ministry of Health, Malaysia.

\section{REFERENCES}

1. Vonkeman HE, van de Laar MAFJ. Nonsteroidal Anti-Inflammatory Drugs: Adverse Effects and Their Prevention. Semin Arthritis Rheum. 2010;39(4):294-312.
2. Botting R. Inhibitors of cyclooxygenases: mechanisms, selectivity and uses. J Physiol Pharmacol. 2006;57:113.

3. Rao P, Knaus EE. Evolution of nonsteroidal anti-inflammatory drugs (NSAIDs): cyclooxygenase (COX) inhibition and beyond. J Pharm Pharm Sci. 2008;11(2):81s-110s.

4. Haag G, Diener H-C, May A, et al. Selfmedication of migraine and tension-type headache: summary of the evidence-based recommendations of the Deutsche. J Headache Pain. 2011;12(2):201-217.

5. Hunt RH, Choquette D, Craig BN, et al. Approach to managing musculoskeletal pain. Can Fam Physician. 2007;53(7):1177-1184.

6. Koffeman AR, Valkhoff VE, Celik S, et al. Highrisk use of over-the-counter non-steroidal antiinflammatory drugs: a population-based crosssectional study. $\mathrm{Br} J$ Gen Pract J R Coll Gen Pract. 2014;64(621):e191-198.

7. Wilcox CM, Cryer B, Triadafilopoulos G. Patterns of use and public perception of overthe-counter pain relievers: focus on nonsteroidal antiinflammatory drugs. J Rheumatol. 2005;32(11):2218-2224.

8. Fosbøl EL, Gislason GH, Jacobsen S, et al. The pattern of use of non-steroidal antiinflammatory drugs (NSAIDs) from 1997 to 2005: a nationwide study on 4.6 million people. Pharmacoepidemiol Drug Saf.

9. Ferraz-Amaro I, Machín S, Carmona L, et al. Pattern of use and safety of non-steroidal antiinflammatory drugs in rheumatoid arthritis patients. A prospective analysis from clinical practice. Reumatol Clin. 2009;5(6):252-258.

10. Gnjidic D, Blyth FM, Le Couteur DG, et al. Nonsteroidal anti-inflammatory drugs (NSAIDs) in older people: Prescribing patterns according to pain prevalence and adherence to clinical guidelines. PAIN®. 2014;155(9):1814-1820.

11. Adams RJ, Appleton SL, Gill TK, et al. Cause for concern in the use of non-steroidal antiinflammatory medications in the community -a population-based study. BMC Fam Pract. 2011;12(1):70.

12. Institute for Public Health (IPH). National Health and Morbidity Survey 2011 (NHMS 2011). Vol. 1: Methodology and General Findings; 2011: 258 Pages. Kuala Lumpur: Ministry of Health Malaysia; 2011. 
13. Turunen JHO, Mäntyselkä PT, Kumpusalo EA, et al. Frequent analgesic use at population level: prevalence and patterns of use. Pain. 2005;115(3):374-381.

14. Zhou Y, Boudreau DM, Freedman AN. Trends in the use of aspirin and nonsteroidal antiinflammatory drugs in the general U.S. population. Pharmacoepidemiol Drug Saf. 2014;23(1):43-50.

15. Plantinga L, Grubbs V, Sarkar U, et al. Nonsteroidal Anti-Inflammatory Drug Use Among Persons With Chronic Kidney Disease in the United States. Ann Fam Med. 2011;9(5):423-430.

16. van Laar M, Pergolizzi JV, Mellinghoff $\mathrm{H}-\mathrm{U}$, et al. Pain Treatment in Arthritis-Related Pain: Beyond NSAIDs. Open Rheumatol J. 2012;6:320-330.

17. Fendrick AM, Greenberg BP. A review of the benefits and risks of nonsteroidal antiinflammatory drugs in the management of mild-to-moderate osteoarthritis. Osteopath Med Prim Care. 2009;3(1):1.

18. Ely LS, Engroff P, Guiselli SR, et al. Use of anti-inflammatory and analgesic drugs in an elderly population registered with a Family Health Program Luísa. Rev Bras Geriatr $E$ Gerontol. 2015;18(3):475-485.

19. Shah S, Mehta V. Controversies and advances in non-steroidal anti-inflammatory drug (NSAID) analgesia in chronic pain management. Postgrad Med J. 2012;88(1036):73-78. doi:10.1136/postgradmedj-2011-130291.

20. Fowler TO, Durham CO, Planton J, et al. Use of nonsteroidal anti-inflammatory drugs in the older adult: Use of NSAIDs in older adults. $J$ Am Assoc Nurse Pract. 2014;26(8):414-423.
21. Pokela N, Bell JS, Lihavainen $\mathrm{K}$, et al. Analgesic use among community-dwelling people aged 75 years and older: a populationbased interview study. Am J Geriatr Pharmacother. 2010;8(3):233-244.

22. Sostres C, Gargallo CJ, Lanas A. Nonsteroidal anti-inflammatory drugs and upper and lower gastrointestinal mucosal damage. Arthritis Res Ther. 2013;15(Suppl 3):S3.

23. Marcum ZA, Hanlon JT. Recognizing the risks of chronic nonsteroidal anti-inflammatory drug use in older adults. Ann Long-Term Care Off $\mathrm{J}$ Am Med Dir Assoc. 2010;18(9):24.

24. Dale O, Borchgrevink PC, Fredheim OMS, et al. Prevalence of use of non-prescription analgesics in the Norwegian HUNT3 population: Impact of gender, age, exercise and prescription of opioids. BMC Public Health. 2015;15(1).

25. Goodin B, Bulls H, Freeman E, et al. Sex differences in experimental measures of pain sensitivity and endogenous pain inhibition. $J$ Pain Res. June 2015:311.

26. Ramírez-Maestre C, Esteve R. The role of sex/gender in the experience of pain: Resilience, fear, and acceptance as central variables in the adjustment of men and women with chronic pain. J Pain. 2014;15(6):608-618.

27. Fillingim RB, King $C D$, Ribeiro-Dasilva $M C$, et al. Sex, Gender, and Pain: A Review of Recent Clinical and Experimental Findings. J Pain Off J Am Pain Soc. 2009;10(5):447-485.

28. Wu AP, Burke A, LeBaron S. Use of traditional medicine by immigrant Chinese patients. Fam Med-Kans CITY-. 2007;39(3):195. 